\title{
Evaluation of Oxidant/Antioxidant Status and Cytokine Levels in Patients with Cannabis Use Disorder
}

\author{
Huseyin Bayazit ${ }^{1}$, Salih Selek ${ }^{2}$, Ibrahim Fatih Karababa ${ }^{3}$, Erdinc Cicek ${ }^{4}$, Nurten Aksoy ${ }^{5}$ \\ ${ }^{1}$ Department of Psychiatry, Siverek State Hospital, Sanliurfa, Turkey, ${ }^{2}$ Harris County Psychiatric Center, University of Texas Health Science Center \\ at Houston, TX, USA, Departments of ${ }^{3}$ Psychiatry and ${ }^{5}$ Clinical Biochemistry, Faculty of Medicine, University of Harran, Sanliurfa, ${ }^{4}$ Department \\ of Psychiatry, Çumra State Hospital, Konya, Turkey
}

\begin{abstract}
Objective: Cannabis is the most commonly used illegal drug in the world and it has several adverse effects such as anxiety, panic reactions and psychotic symptoms. In this study, we aimed to evaluate oxidant, anti-oxidant status and cytokine levels in individuals with cannabis use disorder.

Methods: Thirty-four patients with cannabis use disorder and 34 healthy controls were enrolled to the study. Serum total antioxidant status, total oxidant status and cytokine levels were investigated in patients with cannabis use disorder and healthy controls,

Results: We found increased levels of total oxidant status, oxidative stress index and interleukin (IL) $1 \beta$, IL-6, IL-8, and tumor necrosis factor (TNF) $\alpha$ in individuals with cannabis dependency compared to healthy people. When we compared total antioxidant status, IL-12, and interferon (IFN) $\gamma$ levels, there were no differences in both groups. There was positive correlation between $\mathrm{IL}-6$ and total oxidant status, oxidative stress index levels.

Conclusion: The oxidative balance of individuals with cannabis use disorder was impaired and they had higher levels of IL $-1 \beta$, $\|L-6\| L-$,8 , and $T N F-\alpha$, which is a pro-inflammatory cytokine and indicates increased inflammation compared to healthy controls. Thus, these findings suggest that cannabis increased inflammation and impaired the oxidative balance.
\end{abstract}

KEY WORDS: Cannabis; Oxidants; Antioxidants; Cytokines; Interleukin-6; Interleukin-8.

\section{INTRODUCTION}

Cannabis is the most commonly used illegal drug worldwide. According to the World Health Organization, approximately 147 million people, or $2.5 \%$ of the world population, consume cannabis. ${ }^{1)}$ Cannabis has the lowest initiation age of any illicit drug, and its use often begins during early adolescence. ${ }^{2)}$ Although many people consider cannabis to have few negative side effects, a number of studies have shown that exposure to cannabis is associated with impairments in cognitive processing, ${ }^{3,4)}$ myocardial infarction, and even sudden death. ${ }^{5)}$ Its most common acute adverse effects are anxiety, panic reactions, and psychotic symptoms. ${ }^{6}$ Cannabis has been linked to in-

\footnotetext{
Received: July 14, 2016/ Revised: September 4, 2016

Accepted: September 11, 2016

Address for correspondence: Huseyin Bayazit, MD

Department of Psychiarty, Siverek Devlet Hastanesi, Psikiyatri Bolumu, 06330 Sanliurfa, Turkey.

Tel: +90-414-5521246, Fax: +90-414-5523195

E-mail:drbayazit@yahoo.com

*This study was presented as a poster in 2016 Annual Meeting of Society of Biological Psycchiatry, Atlanta, GA, USA.
}

creased risk of psychiatric disorders. A follow-up study stated that those who had used cannabis by age 18 years were 2.4 times more likely to be diagnosed with schizophrenia. ${ }^{7}$ A relation between depression and frequency of cannabis use in individuals aged 16 years was found. ${ }^{8)}$

Tetrahydrocannabinol (THC) is the major psychoactive component of cannabis, and this compound has been associated with several common effects in the immune system. ${ }^{9)}$ Cytokines are the central signaling molecules of the immune system, as well as a primary regulator of inflammation. Cannabinoids have two main receptor subtypes; the CB1 receptor is mainly expressed by neuronal cells, ${ }^{10)}$ and the CB2 receptor has been isolated in the immune system. ${ }^{11)}$ Following the characterization of these cannabinoid receptors, the association between cannabis and the immune system has been widely studied, but it remains unclear whether cannabis inhibits or enhances the immune system. Previous studies indicated altered cytokine levels and emphasized some cytokines interleukin (IL) 6 , IL-12, and interferon (IFN) $\gamma$ for psychiatric disorders. ${ }^{12,13)}$

(c) This is an Open-Access article distributed under the terms of the Creative Commons Attribution Non-Commercial License (http://creativecommons.org/licenses/by-nc/4.0) which permits unrestricted non-commercial use, distribution, and reproduction in any medium, provided the original work is properly cited. 
It was suggested that IFN- $\gamma$ plays a role by acting to regulate the development of anxiety-like behaviors ${ }^{13)}$ and IL-6 stimulation disrupt normal brain development. ${ }^{14)}$

Oxidative stress reflects and imbalance between the production of free radicals and antioxidant defenses or to repair the resulting damage. In animal studies, Wolff et $a l .{ }^{15)}$ demonstrated that THC impairs the complexes I, II, and III of the mitochondrial respiratory chain and mitochondrial coupling and also it increases brain free radicals production and mitochondrial free radical leakage. Parolini and Binelli ${ }^{16)}$ found that THC caused significant imbalances in oxidative status and enhanced the levels of oxidative stress-induced lipid peroxidation, protein carbonylation, and DNA damage. Many studies have investigated the link between oxidative stress and psychiatric disorders, ${ }^{17-19)}$ but few have evaluated the role of oxidative stress in substance use disorders. Sordi et $a{ }^{20)}$ found positive correlation between reactive substance level and severity of crack cocaine use. Huang et al. ${ }^{21)}$ showed that alcoholic patients had imbalanced oxidative status.

It has been proposed that elevated levels of inflammatory cytokines and oxidative imbalance underlie the development of psychiatric disorders. The present authors further propose that there are links between cannabis and alterations in oxidative status and increased levels of proinflammatory cytokines. Thus, the present study aimed to investigate the oxidative status and immune response of patients with cannabis use disorder.

\section{METHODS}

\section{Subjects}

Research ethics approval was obtained from the Ethics Committee of the Medical School of Harran University (14118). Written informed consent was obtained from all subjects. Thirty-four patients with cannabis dependency between 18 and 35 years of age, diagnosed according to The Diagnostic and Statistical Manuel of Mental Disorders, fifth edition $^{22)}$ (DSM-5) (H.B.) in the outpatient Psychiatry Department of Harran University Hospital were involved. All of the individuals in the patient group were using cannabis at the time of sampling and had positive urine cannabinoid test. Exclusion criteria were as follows: any other substance use disorders except nicotine, any other psychiatric disorders, taking any medications, presence of severe organic condition, presence of epilepsy and severe neurologic disorder, presence of infectious disease, excessive obesity and insufficient sampling. The control group is formed of 34 healthy male subjects who were chosen among the university students and hospital staff. All control subjects had no history of cannabis use. These were free of any medication for at least 6 weeks prior to blood sampling. Patients and controls were matched for sociodemographic characteristics such as age, gender, education years and body weight. As all patients smoke cigarette, we composed the control group with smokers. None of the control subjects were alcohol drinker, or had ever taken psychotropic drugs. They had no history of psychiatric or neurological disorders.

\section{Blood Samples and Meusurements}

We searched literature in regard of association between cytokines and illicit drugs and psychiatric disorders. As a result, we decided to investigate potential candidates such as IL-1 $\beta$, IL-6, IL-8, and tumor necrosis factor (TNF) $\alpha$ and total oxidant status (TOS), oxidative stress index (OSI). Serum total antioxidant status (TAS), TOS, OSI, IL-1 $\beta$, IL-6, IL-8, IL-1 2 and TNF- $\alpha$ and IFN- $\gamma$ levels were measured in both groups. After 12-hour fasting, venous blood samples from left forearm vein were collected during routine laboratory evaluation at $8 \mathrm{am}$. Venous blood was extracted into serum tubes and centrifuged for 10 minutes at 5,000 rpm. Serum samples were then stored at $-80^{\circ} \mathrm{C}$ until the analysis. Plasma samples were analyzed via enzyme-linked immunosorbent assay (ELISA) for IL-12 p70 (eBioscience), IL-6 (Dia Source), IFN- $\gamma$ (Dia Source), IL-1 $\beta$ (Dia Source), IL-8 (Dia Source), and TNF- $\alpha$ (Dia Source).

TAS of the serum was measured using a novel automated colorimetric measurement method developed by Erel. $^{23)}$ The assay results are expressed as mmol Trolox $\mathrm{Eq} / \mathrm{L}$, and the precision of this assay is excellent, being lower than $3 \% .{ }^{24)}$ TOS of the serum were measured using a novel automated colorimetric measurement method developed by Erel. ${ }^{25)}$ This method is rapid, easy, stable, reliable, sensitive, inexpensive and fully automated. The developed method has high linearity and the results are highly reproducible. The reagents are easy to prepare and their lifetimes are long. ${ }^{23,25)}$ The assay is calibrated with hydrogen peroxide and the results are expressed in terms of micromolar hydrogen peroxide equivalent per liter $(\mu \mathrm{mol}$ $\mathrm{H}_{2} \mathrm{O}_{2} \mathrm{Eq} / \mathrm{L}$ ). OSI was calculated as TOS/TAS ratio. ${ }^{26)}$

\section{Statistical Analysis}

The data were analyzed using Statistical Package for Social Sciences (SPSS) for Windows version 15.0 (SPSS Inc., Chicago, IL, USA). The Kolmogorov-Smirnov test was used to determine whether the data were distributed 
normally. The significance of differences between groups was estimated by $t$ test and Mann Whitney $U$ test. Parametric tests were used for normal distribution. We used Pearson test for correlation. The results for parametric tests were expressed as the mean \pm standard deviation. The results for non-parametric tests were expressed as the median \pm interquartile range. A $p$ value less than 0.05 were considered as statistically significant.

\section{RESULTS}

This study included 34 patients with cannabis use disorder with a mean age of $26 \pm 9$ years and 34 healthy controls with a mean age of $26 \pm 8$ years. No statistically significant differences were detected in age and sex between the two groups $(p>0.05)$. Mean duration of cannabis use was $55 \pm 7$ months in patient groups (Table 1).

The patient and healthy control groups did not significantly differ in terms of age or gender $(p>0.05)$. There were statistically significant increase in the TOS, OSI, and IL-1 $\beta$, IL-6, IL- 8 , and TNF- $\alpha$ levels of the patients compared to the controls, but there were no significant differences in the TAS, IL-12, or IFN- $\gamma$ levels between the two groups. Additionally, IL-6 levels were positively, mild statistically significantly correlated with TOS $(\mathrm{r}=0.411$, $p=0.001)$ and also correlated with OSI levels ( $\mathrm{r}=0.409$, $p=0.001)$. But there were no statistically signifacant correlation between the TAS, TOS, OSI, IL-12, and IFN- $\gamma$ levels in patients. The TAS, TOS, OSI, IL-1 $\beta$, IL-6, IL- 8 , IL-12, TNF- $\alpha$, and IFN- $\gamma$ levels are provided in Table 2. There were no statistically correlations between duration of cannabis use and oxidant, anti-oxidant and cytokines.

\section{DISCUSSION}

In the present study, there was a significant increase in the levels of IL-1 $\beta$, IL-6, IL-8, and TNF- $\alpha$ in patients with cannabis dependency, but no significant differences between the patients and controls were observed in terms of IL-12 and IFN- $\gamma$ levels. To our knowledge, this is first study to evaluate cytokine levels in patients with

Table 1. Sociodemographic information of participants*

\begin{tabular}{lccc}
\hline & $\begin{array}{c}\text { Subject } \\
(n=34)\end{array}$ & $\begin{array}{c}\text { Control } \\
(n=34)\end{array}$ & p value \\
\hline Age $(\mathrm{yr})$ & $\begin{array}{l}26.72 \pm 9.45 \\
55.67 \pm 7.23\end{array}$ & $26.36 \pm 8.13$ & 0.989 \\
Duration of substance use (mo) & & \\
\hline
\end{tabular}

Values are presented as mean \pm standard deviation.

${ }^{*}$ All participants were males. dependency. IL-1 $\beta$, IL-6, IL-8, and TNF- $\alpha$ have important role in proinflammatory process. Many psychiatric disorders are associated with altered cytokine levels. For example, patients with major depression had increased TNF- $\alpha$, IL- 6 , and IL-1 $\beta$ levels, ${ }^{27)}$ and antidepressants may reverse the inflammatory process. ${ }^{28)}$ Korczak et al. ${ }^{29)}$ reported that cytokines were responsible for depressive symptoms in patients with type 1 diabetes, and Westling et al. ${ }^{30)}$ found that IL- $1 \beta$ reactivity was associated with symptoms of hostility. Accordingly, Müller et al. ${ }^{31)}$ determined that patients with schizophrenia who were treated with adjunctive nonsteroidal anti-inflammatory agents exhibited significant improvements in total symptoms. Pedrini et al. ${ }^{32)}$ observed that schizophrenic patients exhibit increased levels of IL- 6 but decreased levels of IL-10. In another study, the IL-6 levels of acutely relapsed inpatients and first-episode psychosis patients were elevated, but antipsychotic treatment normalized these levels. $^{33)}$

Despite these findings, the effects of cannabis on the immune system are contradictory. Several factors such as acute or chronic administration, dose and inhalation or digestion of cannabis may contribute to this contradictory. Jan et al. $^{34)}$ suggested that cannabidiol markedly suppressed humoral immunity, and another study found that high-dose cannabis suppressed resistance to infection. ${ }^{35)}$ However, these studies administered cannabis at levels that were much higher than a human could tolerate, 100 to 1,000 times higher than the THC levels in the blood of addicted people. ${ }^{36)}$ At physiological doses, cannabis may stimulate the immune system rather than suppress it, which suggests that this drug has dose-dependent effects. ${ }^{37)}$ Beside cannabis, other illicit drugs have effects on immune system. Narvaez et al. ${ }^{38)}$ reported that patients with

Table 2. Oxidant, antioxidant and cytokine levels of participants

\begin{tabular}{lccc}
\hline & $\begin{array}{c}\text { Subject } \\
(\mathrm{n}=34)\end{array}$ & $\begin{array}{c}\text { Control } \\
(\mathrm{n}=34)\end{array}$ & $p$ value \\
\hline $\mathrm{TAS}(\mu \mathrm{mol}$ Trolox Eq/L)* & $0.99 \pm 0.12$ & $1.02 \pm 0.11$ & 0.352 \\
$\mathrm{TOS}\left(\mu \mathrm{mol} \mathrm{H} \mathrm{O}_{2} \mathrm{Eq} / \mathrm{L}\right)^{\dagger}$ & $42.1 \pm 16.79$ & $12.71 \pm 5.26$ & $<0.0001$ \\
$\mathrm{OSI}^{\dagger}$ & $4.00 \pm 1.72$ & $1.213 \pm 0.49$ & $<0.0001$ \\
$\mathrm{IL}^{+} \beta(\mathrm{pg} / \mathrm{ml})^{*}$ & $47.00 \pm 12.75$ & $28.03 \pm 8.30$ & $<0.0001$ \\
$\mathrm{IL}-6(\mathrm{pg} / \mathrm{ml})^{*}$ & $17.75 \pm 5.17$ & $12.15 \pm 3.48$ & $<0.0001$ \\
$\mathrm{IL}-8(\mathrm{pg} / \mathrm{ml})^{*}$ & $46.65 \pm 14.10$ & $24.49 \pm 6.82$ & $<0.0001$ \\
$\mathrm{IL}-12 \mathrm{p} 70(\mathrm{pg} / \mathrm{ml})^{\dagger}$ & $7.37 \pm 1.51$ & $7.31 \pm 1.69$ & 0.917 \\
$\mathrm{IFN}-\gamma(\mathrm{IU} / \mathrm{ml})^{*}$ & $0.41 \pm 0.07$ & $0.40 \pm 0.05$ & 0.149 \\
$\mathrm{TNF}-\alpha(\mathrm{pg} / \mathrm{ml})^{* *}$ & $7.99 \pm 1.56$ & $7.07 \pm 1.08$ & 0.007 \\
\hline
\end{tabular}

*Independent $t$ test was used and expressed as mean \pm standard deviation.

${ }^{\dagger}$ Mann-Whitney $U$ test was used and expressed as median \pm interquartile range. 
crack cocaine use disorder had higher circulating levels of IL-1 $\beta$, TNF- $\alpha$ and IL-10. Byrd et al. ${ }^{39)}$ suggest that opiate addiction had immunosuppressive role in the brain. CB2 receptors have focus on its role in the immune system. ${ }^{11}$ Accumulating evidence showed that $\mathrm{CB} 2$ receptors are widely expressed in the brain, especially microglia and neurons. ${ }^{40)}$

The present study also found that patients with cannabis dependency had significantly higher levels of TOS and OSI than did healthy control subjects, although there was no difference in TAS levels. The relationship between psychiatric disease and oxidative stress has been extensively researched, and an imbalanced oxidative status has been implicated in bipolar disorder, ${ }^{18,41)}$ adult attention deficit hyperactivity disorder, ${ }^{17)}$ generalized anxiety disorder, ${ }^{42)}$ and panic disorder. ${ }^{43)}$ However, the role that oxidative stress plays in substance use disorders remains unclear. Sordi et $\mathrm{al}^{20)}$ found positive correlation between reactive substance level and severity of crack cocaine use. Huang et al. ${ }^{21)}$ showed that alcoholic patients had imbalanced oxidative status. THC increases oxidative stress and induces cerebral mitochondrial dysfunction via enhancements in $\mathrm{H}_{2} \mathrm{O}_{2}$ production in the mitochondria. ${ }^{15)} \mathrm{In}$ the present study, IL-6 showed positive correlations with TOS and OSI. The activation of CB1 receptors in astrocytes increases glucose oxidation, ${ }^{44)}$ and IL- 6 , which is pro-inflammatory, is synthesized by astrocytes. The production of reactive oxygen species is closely associated with the production of energy, and thus is directly associated with mitochondrial activity. ${ }^{45)}$ The brain is the most energy-consuming organ in the body, and the balance between oxidants and antioxidants is very important for brain aging. ${ }^{46)}$ Free radicals in the body induce oxidative damage to cellular components, genetic materials, a process which results in altered cellular function and genetic expression, deteriorated tissue and organ function, and eventually death. In our previous study, we found increased S100B levels in cannabis use disorder, which indicates neuronal damage. ${ }^{47)}$ Regulation of gene expression is a significant mechanism by which chronic exposure to an illicit drug causes long-lasting changes in the brain that underlie the behavioral abnormalities that characterize a state of addiction. ${ }^{48)}$ And oxidative stress and inflammation may have role in this process.

The present study has several limitations that should be noted. First, the sample size was relatively small (34 patients, 34 controls) and all patients were male, so the effects of gender could not be investigated. Second, we measured the cannabis in urine as positive or negative so we didn't measure the amount of the cannabis that patients used. Next studies should take into consideration the frequency and amount of used cannabis. On the other hand, the present study was the first to evaluate cytokine activity and oxidative status in patients with cannabis use disorder.

In conclusion, the oxidative balance of individuals with cannabis use disorder was impaired and they had higher levels of IL-1 $\beta$, IL-6, IL-8, and TNF- $\alpha$, which is a pro-inflammatory cytokine and indicates increased inflammation compared to healthy controls. Thus, these findings suggest that cannabis increased inflammation and impaired the oxidative balance in patients with cannabis use disorder. The inflammation and oxidative stress, which cannabis caused, associated neuronal damage and neuronal death may lead to permanent behavioral abnormalities and clinical implications such as cognitive impairment, anxiety, depression and psychotic symptoms. Next studies should focus on these associations and investigate the role of anti-inflammatory and anti-oxidant treatment in cannabis use disorder.

\section{- Acknowledgments}

This study was funded by Harran University Board of Scientific Research Projects (funding number: 14118).

\section{REFERENCES}

1. World Health Organization. Management of substance abuse. Facts and figures [Internet]. WHO; 2016 [cited at 2015 Jul 29]. Available from: http://www.who.int/ substance_abuse/facts/en/.

2. Hall W, Solowij N. Adverse effects of cannabis. Lancet 1998;352:1611-1616.

3. Ramaekers JG, Berghaus G, van Laar M, Drummer OH. Dose related risk of motor vehicle crashes after cannabis use. Drug Alcohol Depend 2004;73:109-119.

4. Bhattacharyya S, Morrison PD, Fusar-Poli P, Martin-Santos $\mathrm{R}$, Borgwardt S, Winton-Brown $\mathrm{T}$, et al. Opposite effects of delta-9-tetrahydrocannabinol and cannabidiol on human brain function and psychopathology. Neuropsychopharmacology 2010;35:764-774.

5. Thomas G, Kloner RA, Rezkalla S. Adverse cardiovascular, cerebrovascular, and peripheral vascular effects of marijuana inhalation: what cardiologists need to know. Am J Cardiol 2014;113:187-190.

6. Hall W, Pacula RL. Cannabis use and dependence: public health and public policy. Cambridge, UK:Cambridge University Press;2003.

7. Andréasson S, Allebeck P, Engström A, Rydberg U. Cannabis and schizophrenia. A longitudinal study of Swedish conscripts. Lancet 1987;2:1483-1486.

8. Fergusson DM, Horwood LJ. Early onset cannabis use and psychosocial adjustment in young adults. Addiction 1997; 92:279-296.

9. Nahas G, Latour C. The human toxicity of marijuana. Med J Aust 1992;156:495-497.

10. Devane WA, Dysarz FA 3rd, Johnson MR, Melvin LS, 
Howlett AC. Determination and characterization of a cannabinoid receptor in rat brain. Mol Pharmacol 1988; 34:605-613.

11. Munro S, Thomas KL, Abu-Shaar M. Molecular characterization of a peripheral receptor for cannabinoids. Nature 1993;365:61-65.

12. Pallavi P, Sagar R, Mehta M, Sharma S, Subramanium A, Shamshi F, et al. Serum cytokines and anxiety in adolescent depression patients: Gender effect. Psychiatry Res 2015; 229:374-380.

13. Tükel R, Arslan BA, Ertekin BA, Ertekin E, Oflaz S, Ergen $\mathrm{A}$, et al. Decreased IFN- $\gamma$ and IL-12 levels in panic disorder. J Psychosom Res 2012;73:63-67.

14. Brown JA, Sherrod SD, Goodwin CR, Brewer B, Yang L, Garbett KA, et al. Metabolic consequences of interleukin-6 challenge in developing neurons and astroglia. J Neuroinflammation 2014;11:183.

15. Wolff V, Schlagowski AI, Rouyer O, Charles AL, Singh F, Auger $\mathrm{C}$, et al. Tetrahydrocannabinol induces brain mitochondrial respiratory chain dysfunction and increases oxidative stress: a potential mechanism involved in cannabis-related stroke. Biomed Res Int 2015;2015:323706.

16. Parolini M, Binelli A. Oxidative and genetic responses induced by A-9-tetrahydrocannabinol (4-9-THC) to Dreissena polymorpha. Sci Total Environ 2014;468-469:68-76.

17. Selek S, Bulut M, Ocak AR, Kalenderoğlu A, Savaş HA. Evaluation of total oxidative status in adult attention deficit hyperactivity disorder and its diagnostic implications. $J$ Psychiatr Res 2012;46:451-455.

18. Savas HA, Gergerlioglu HS, Armutcu F, Herken H, Yilmaz $\mathrm{HR}$, Kocoglu E, et al. Elevated serum nitric oxide and superoxide dismutase in euthymic bipolar patients: impact of past episodes. World J Biol Psychiatry 2006;7:51-55.

19. Kandemir H, Abuhandan M, Aksoy N, Savik E, Kaya C. Oxidative imbalance in child and adolescent patients with obsessive compulsive disorder. J Psychiatr Res 2013;47: 1831-1834.

20. Sordi AO, Pechansky F, Kessler FH, Kapczinski F, Pfaffenseller B, Gubert $\mathrm{C}$, et al. Oxidative stress and BDNF as possible markers for the severity of crack cocaine use in early withdrawal. Psychopharmacology (Berl) 2014;231: 4031-4039.

21. Huang MC, Chen CC, Peng FC, Tang SH, Chen CH. The correlation between early alcohol withdrawal severity and oxidative stress in patients with alcohol dependence. Prog Neuropsychopharmacol Biol Psychiatry 2009;33:66-69.

22. American Psychiatric Association. Diagnostic and Statistical Manual of Mental Disorders, fifth edition (DSM-5). Arlington, VA:American Psychiatric Association;2013.

23. Erel O. A novel automated method to measure total antioxidant response against potent free radical reactions. Clin Biochem 2004;37:112-119.

24. Cao G, Prior RL. Comparison of different analytical methods for assessing total antioxidant capacity of human serum. Clin Chem 1998;44:1309-1315.

25. Erel O. A new automated colorimetric method for measuring total oxidant status. Clin Biochem 2005;38:1103-1111.

26. Kosecik M, Erel O, Sevinc E, Selek S. Increased oxidative stress in children exposed to passive smoking. Int J Cardiol 2005;100:61-64.

27. Hannestad J, DellaGioia N, Bloch M. The effect of antidepressant medication treatment on serum levels of inflammatory cytokines: a meta-analysis. Neuropsychopharmacology 2011;36:2452-2459.

28. Hashioka S. Antidepressants and neuroinflammation: Can antidepressants calm glial rage down? Mini Rev Med Chem 2011;11:555-564.

29. Korczak DJ, Pereira S, Koulajian K, Matejcek A, Giacca A. Type 1 diabetes mellitus and major depressive disorder: evidence for a biological link. Diabetologia 2011;54: 2483-2493.

30. Westling S, Ahrén B, Träskman-Bendz L, Brundin L. Increased IL-1 $\beta$ reactivity upon a glucose challenge in patients with deliberate self-harm. Acta Psychiatr Scand 2011;124:301-306.

31. Müller N, Krause D, Dehning S, Musil R, Schennach-Wolff $\mathrm{R}$, Obermeier $\mathrm{M}$, et al. Celecoxib treatment in an early stage of schizophrenia: results of a randomized, double-blind, placebo-controlled trial of celecoxib augmentation of amisulpride treatment. Schizophr Res 2010;121:118-124.

32. Pedrini M, Massuda R, Fries GR, de Bittencourt Pasquali MA, Schnorr CE, Moreira JC, et al. Similarities in serum oxidative stress markers and inflammatory cytokines in patients with overt schizophrenia at early and late stages of chronicity. J Psychiatr Res 2012;46:819-824.

33. Miller BJ, Buckley P, Seabolt W, Mellor A, Kirkpatrick B. Meta-analysis of cytokine alterations in schizophrenia: clinical status and antipsychotic effects. Biol Psychiatry 2011;70:663-671.

34. Jan TR, Su ST, Wu HY, Liao MH. Suppressive effects of cannabidiol on antigen-specific antibody production and functional activity of splenocytes in ovalbumin-sensitized BALB/c mice. Int Immunopharmacol 2007;7:773-780.

35. Morahan PS, Klykken PC, Smith SH, Harris LS, Munson AE. Effects of cannabinoids on host resistance to Listeria monocytogenes and herpes simplex virus. Infect Immun 1979;23:670-674.

36. Sánchez C, Velasco G, Guzmán M. Metabolic stimulation of mouse spleen lymphocytes by low doses of delta9tetrahydrocannabinol. Life Sci 1997;60:1709-1717.

37. Berdyshev EV, Boichot E, Germain N, Allain N, Anger JP, Lagente V. Influence of fatty acid ethanolamides and delta9-tetrahydrocannabinol on cytokine and arachidonate release by mononuclear cells. Eur J Pharmacol 1997;330: 231-240.

38. Narvaez JC, Magalhães PV, Fries GR, Colpo GD, Czepielewski LS, Vianna P, et al. Peripheral toxicity in crack cocaine use disorders. Neurosci Lett 2013;544:80-84.

39. Byrd D, Murray J, Safdieh G, Morgello S. Impact of opiate addiction on neuroinflammation in HIV. J Neurovirol 2012;18:364-373.

40. Atwood BK, Mackie K. CB2: a cannabinoid receptor with an identity crisis. $\mathrm{Br} J$ Pharmacol 2010;160:467-479.

41. Gergerlioglu HS, Savas HA, Bulbul F, Selek S, Uz E, Yumru M. Changes in nitric oxide level and superoxide dismutase activity during antimanic treatment. Prog Neuropsychopharmacol Biol Psychiatry 2007;31:697-702.

42. Emhan A, Selek S, Bayazıt H, Fatih Karababa İ, Katı M, Aksoy N. Evaluation of oxidative and antioxidative parameters in generalized anxiety disorder. Psychiatry Res 2015;230:806-810.

43. Ersoy MA, Selek S, Celik H, Erel O, Kaya MC, Savas HA, et al. Role of oxidative and antioxidative parameters in etiopathogenesis and prognosis of panic disorder. Int $J$ Neurosci 2008;118:1025-1037.

44. Cota D. Role of the endocannabinoid system in energy balance regulation and obesity. Front Horm Res 2008; 36:135-145.

45. Gemma C, Vila J, Bachstetter A, Bickford PC. Oxidative stress and the aging brain: from theory to prevention. In: 
Riddle DR, editor. Brain aging: Models, methods, and mechanisms. Boca Raton, FL:CRC Press;2007.

46. Genova ML, Pich MM, Bernacchia A, Bianchi C, Biondi A, Bovina $\mathrm{C}$, et al. The mitochondrial production of reactive oxygen species in relation to aging and pathology. Ann NY Acad Sci 2004;1011:86-100.
47. Bayazit H, Cicek E, Selek S, Aksoy N, Karababa IF, Kandemir $\mathrm{H}$, et al. Increased S100B levels in cannabis use disorder. Eur Addict Res 2016;22:177-180.

48. Nestler EJ. Transcriptional mechanisms of drug addiction. Clin Psychopharmacol Neurosci 2012;10:136-143. 